\title{
DIKKAT EKSIKLIĞi HIPERAKTIVITE BOZUKLUĞU OLAN ÇOCUKLARDA UYKU SORUNLARI VE KLINIK DEĞiŞKENLERLE iLIŞKISi
}

\author{
P. Öner*, Ö.Ş. Üneri ${ }^{*}$ B. Rezaki ${ }^{*}$ Ş. Bodur ${ }^{*}$
}

\begin{abstract}
ÖZET
Amaç: Dikkat Eksikliği Hiperaktivite Bozukluğu (DEHB) ve uyku sorunları arasında gerek nesnel gerek öznel ölçüm araçları kullanılarak yapılan araştırmalar, uyku sorunlarının DEHB olgularında daha sık görüldüğünü göstermektedir. Bu çalışmada DEHB hastalarında bildirilen uyku sorunlarının ve bunların DEHB alt gruplarıyla ve eş tanılarla ilişkisinin incelenmesi amaçlanmıştır. Yöntem: Araştırmaya 8,9 $\pm 2,8$ (SD) yaş ortalamasında 73 DEHB ve yaş ve cinsiyet bakımından eşleştirilmiş 41 Sağlıklı olgu alınmıştır. Tüm olgular Kiddie -SADS-Present and Lifetime Version (Şimdi ve Yaşam Boyu şekli) (KSADS-PL) yarı-yapılandırılmış görüşme ile değerlendirilmiş; DEHB tanısı ve eştanılar DSM-IV tanı ölçütleri esas alınarak konulmuştur. Uyku sorunlarına dair verilerin toplanması amacıyla anne-babaların doldurduğu Pediatrik Uyku Ölçeği (PUÖ) kullanılmıştır. Bulgular: DEHB olgularının uykuyla ilişkili solunum bozuklukları Nefes Alma, Uykululuk ve Diğer Sorunlar
\end{abstract} * Dr., Dr. Sami Ulus Çocuk Sağlığı ve Hastalıkla-
rı, Çocuk-Ergen Psikiyatrisi Bölümü puanları ve toplam puan kontrol olgularından anlamlı olarak yüksektir. Nefes Sorunları puanı DEHB olgularında daha yüksektir ancak istatistiksel olarak anlamlı bulunmamıştır $(p=0.08)$. Bileşik tip ve dikkat eksikliğinin baskın olduğu DEHB olguları arasında uyku sorunları puanları açısından farklılık saptanmamıştır. Eştanı durumlarının varlığı da uyku sorunlarını etkilememektedir. Sonuç: Önceki yazın ile uyumlu biçimde DEHB olgularında kontrollerden anlamlı düzeyde fazla uyku sorunu bulunduğu saptanmıştır; ancak eştanı bulunması ile uyku sorunlarının düzeyi arasına anlamlı bir ilişki tespit edilmemiştir.

Anahtar Sözcükler: Çocuk, uyku, Dikkat Eksikliği Hiperaktivite Bozukluğu (DEHB), Pediatrik Uyku Ölçeği (PUÖ), eştanı.

\section{Sleep Problems and Their Clinical Correlations in Children with Attention Deficit Hyperactivity Disorder}

\section{SUMMARY}

Purpose: Results from both subjective and objective studies have reported that children with Attention Deficit Hyperactivity Disorder 
(ADHD) had higher sleep-related problems than controls. The aim of the study is to assess the relationship between sleep problems and ADHD subtypes and ADHD comorbidities. Method: Subjects were 73 ADHD patients and 41 healthy controls mean age of 8,9 $\pm 2,8$ (SD) who diagnosed with Kiddie -SADS-Present and Lifetime version (KSADS-PL), a semi-structured clinical schedule. Parents completed Pediatric Sleep Questionnaire (PSQ) to assess sleep-related problems. Findings: Subjects with ADHD had higher PSQ Behavior, Sleepiness and Other Problems scores when compared with control subjects. ADHD subjects also had higher Breathing score, which showed a statistical trend to significance $(p=0.08)$. PSQ Sleepiness, Breathing and Other problems scores were not different between subjects with combined type or inattnetive types of ADHD. Comorbidity did not significantly effect PSQ scores. Results: The results are compatible with the previous literature and showed that ADHd cases have significantly higher sleep-related problems, but there is no significant relationship between ADHD comorbidities and level of sleep problems.

Key Words: Child, sleep, Attention Deficit Hyperactivity Disorder (ADHD), Pediatric Sleep Questionnaire (PSQ), comorbidity.

\section{Giriş}

Dikkat Eksikliği Hiperaktivite Bozukluğu (DEHB) DSM-IV'e göre, kronik dikkatsizlik ve/veya dürtüsellik-hiperaktivite örüntüsü ile kendini gösteren; 7 yaşından önce başlamış olan ve en az iki farklı ortamda bu örüntülerin var olmasının gerektiği bir bozukluktur (APA, 2004). Okul çağı çocuklarında sıklığı \% 8-12 olarak öngörülmekte (Biederman ve Faraone 2005), sık görülen bir bozukluk olması dolayısıyla hakkında oldukça fazla sayıda araştırma yapılmaktadır. Son yıllarda özellikle uyku bozuklarıyla ilişkisi üzerinde durulmaktadır. Uyku bozukluğu olan çocukların belirtileri ile DEHB olan çocukların belirtilerinin benzerlik gösterdiğinin fark edilmesi (Chervin ve Archbold 2002) ve DEHB tedavisinde ilk seçenek olarak kullanılan stimülanların uyku üzerine olumsuz etkilerinin olduğunun düşünülmesi (Efron ve ark 1997) bu merakı tetiklemişsir.

$\mathrm{Bu}$ araştırmaların bir kısmı polisomnografi, aktigrafi, infrared video kamera, Çoklu Uyku Latansı Testi [Multiple Sleep Latency Test (MSLT)] gibi nesnel ölçüm araçları ile (Golan ve ark 2004, Huang 2004); bir kısmı ise annebabaların doldurduğu ölçeklerin değerlendirilmesi (Owens ve ark 2000) şeklinde öznel ölçüm araçları kullanılarak yapılmışır. 2006 yılında Cortese ve arkadaşlarının yaptığı sistematik gözden geçirmeye göre araştırmaların önemli bir kısmında yöntem sorunları bulunmaktadır ve veriler henüz kesin bir çıkarımda bulunmak için yetersizdir ancak MSLT'de DEHB olan çocukların kontrollere oranla daha sık uykuya geçtiklerini ve uyku esnasında kaslarında daha fazla kasılma meydana geldiğini ve daha yüksek sayıda apne-hipopne indeksine sahip olduklarını göstermektedir. Ülkemizdeki yazın incelendiğinde günümüze kadar DEHB olan çocuklarda uyku sorunlarına ilişkin bir araştırmaya rastlanmamıştır.

Bu çalışmada DEHB hastalarında bildirilen uyku sorunlarının ve bunların DEHB alt gruplarıyla ve eş tanılarla ilişkisinin incelenmesi amaçlanmıştır. Ülkemiz DEHB çocuklarında da uyku sorunlarının ilk kez değerelendiriliyor olması açısından da katkıda bulunacağı düşünülmüştür.

\section{YÖNTEM}

Örneklem: 2007 yılında Dr. Sami Ulus Çocuk Hastanesine başvurusu olup öncelikle Genel Pediatri polikliniğinde genel tıbbi değerlendirme ve fizik muayeneleri yapıldıktan sonra Çocuk-Ergen Psikiyatrisi polikliniğine yönlendirilen olgular arasından birincil başvuru şikayeti uyku sorunları olmayan ya da bu nedenden ötürü konsulte edilmeyen, daha önce tedavi almamış ve ilk kez tanı konulan 4-14 yaş ara- 
lığında 73 DEHB (20 kız 53 erkek) olgusu araştırmaya dahil edilmiştir. Olgularda dışlama ölçütleri olarak zihinsel gelişme geriliği bulunması, akut ya da kronik genel tıbbi bir hastalığının bulunması, anne-babada zihinsel gerilik bulunması ya da okur yazar olmaması belirlenmiştir.

Kontrol grubu ise herhangi bir akut ya da kronik hastalığı ya da mental bozukluğu (psikopatolojisi) olmayan; anne-babasında zihinsel gelişme geriliği bulunmayan ve okur yazar olan 41 gönüllü çocuk (12 kız 29 erkek) ve annebabalarından oluşmaktadır.

Anne-babalar ve çocukları araştırmanın amacı ile ilgili olarak bilgilendirilmiş ve onayları alınmıştır.

Değerlendirme araçları: Hem DEHB hem kontrol grubu Kiddie -SADS-Present and Lifetime version (Şimdi ve Yaşam Boyu şekli) (KSADS-PL) yarı-yapılandırmış görüşme (Kaufman ve ark 1997) ile değerlendirilmiş; DEHB tanısı ve alt grupları ve eşzamanlı diğer psikiyatrik tanılar bu görüşme temel alınarak konulmuştur. KSADS-PL'in Türkçe geçerlik ve güvenirliği yapılmış olup çocuk ve ergenlerde etkin bir tanı aracı olduğu düşünülmektedir (Gökler ve ark 2004).

Tüm olguların anne-babalarından çocuklarının uyku sorunlarını değerlendirmek amacıyla Pediatrik Uyku Ölçeği (070424 numaralı versiyonu) (Chervin ve ark 2000) doldurmaları istenmiş; veri kaybını önlemek amacıyla eksik ya da anlaşılmayan sorular anne-babalara eşliğinde gözden geçirilmiştir. Form, (A) gece ve uyku zamanı olan davranışlar, (B) gün içerisindeki davranışlar ve (C) diğer bilgiler olmak üzere üç bölümden ve toplam 72 maddeden oluşmaktadır. Araştırmada 72 maddelik form kullanılmıştır. DEHB ile ilişkili ana maddeler (C) bölümünde yer almaktadır ancak B24 ve B25 maddeleri de doğrudan DEHB ile ilişkilidir. Chervin ve arkadaşları tarafında yapılan geçerlik-güvenirlik çalışmalarında Pediatrik Uyku Ölçeği içinden 22 sorunun uykuyla ilişkili davranış so- runlarını daha iyi ölçtüğü görülmüştür ve bu sorulardan daha sonra Uyku İle İlişkili Davranışsal Sorunlar [Sleep Related Behavior Disorders (SRBD)] ölçeği türetilmiştir. Yapılan çalışmalara göre ölçeğin Davranışsal Sorunlar, Uykululuk, Nefes Sorunları ve Diğer Sorunlar olmak üzere dört alt ölçeği bulunmaktadır (Chervin ve ark 2000). Davranışsal Sorunlar ve Diğer Sorunlar alt ölçekleri, DEHB ile ilgili maddeler içermektedir.

Pediatrik Uyku Ölçeği (PUÖ)'nin Türkçe geçerlik ve güvenirliğine dair henüz veri bulunmamaktadır. Ancak uyku sorunlarını değerlendirebilecek Türkçe ölçek ya da başka bir detaylı değerlendirme aracı bulunmadığından PUÖ seçilmiştir ve geçerlik güvenirliğine dair çalışma halen kliniğimizde yürütülmeye devam etmektedir.

Grupların sürekli değişkenler açısından karşıllaştırılması varyans analizi ile, kategorik değişkenlerin karşılaştırılması ise ki-kare testi ile yapılmıştır. $p<0.05$ değeri istatistiksel olarak anlamlı kabul edilmiştir. Analizler SPSS 13.0 istatistiksel analiz programı ile gerçekleştirilmiştir.

\section{BULGULAR}

DEHB (53 erkek-20 kız) ve kontrol (29 erkek-12 kız ) gruplarının cinsiyet dağılımları arasında anlamlı farklılık yoktur (x2=0.04, $p>0.8)$. İki grubun yaş ortalamaları arasında da istatistiksel fark bulunmamaktadır $(F(1,112)=$ $0.6, p>0.4)$.

DEHB ve kontrol olgularının Uyku ile Illişkili Davranışsal Sorunlar (UiDB) ölçeğinden aldıkları toplam ve alt ölçek puanları Tablo1'de özetlenmiştir. Tablo 1'de izlendiği gibi DEHB olguları Nefes Sorunları alt ölçeği dışında (DEHB:1.3 \pm 1.6; Kontrol: $0.82 \pm 1.1, F(1,112)=3.2, p=0.08)$, hem tüm alt ölçeklerden hem de toplamda kontrollerden daha yüksek puan almışlardır. DEHB grubunun kontrol grubuna göre Davranışsal

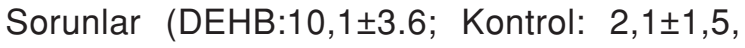
$F(1,112)=179.7, p<0.0001$ ), Uykululuk (DEHB: 
Tablo 1: DEHB ve kontrol olgularının Uyku ölçeğinden aldıkları toplam ve alt ölçek puanları.

\begin{tabular}{|l|c|c|c|c|}
\hline Puan & $\begin{array}{c}\text { DEHB } \\
(\mathrm{n}=73)\end{array}$ & $\begin{array}{l}\text { Kontrol } \\
(\mathrm{n}=14)\end{array}$ & $\mathrm{F}(1.112)$ & $\mathrm{p}$ \\
\hline Nefes Sorunları & $1.3 \pm 1.6$ & $.82 \pm 1.1$ & 3.2 & 0.08 \\
\hline Davranışsal Sorunlar & $10.1 \pm 3.6$ & $2.1 \pm 1.5$ & 179.7 & $<0.0001$ \\
\hline Uykululuk & $0.20 \pm 0.53$ & $0 \pm 0$ & 6.2 & 0.014 \\
\hline Diğer & $1.12 \pm 0.92$ & $0.63 \pm 0.66$ & 8.86 & 0.004 \\
\hline Toplam & $0.58 \pm 0.21$ & $0.16 \pm 0.11$ & 142.7 & $<0.0001$ \\
\hline Toplam Uyku & $0.16 \pm 0.15$ & $0.09 \pm 0.08$ & 8.6 & 0.004 \\
\hline
\end{tabular}

Tablo 2: DEHB bileşik tip ve DEB olgularının karşılaştııııması.

\begin{tabular}{|l|l|l|c|c|}
\hline Puan & $\begin{array}{l}\text { Birleşik Tip } \\
(\mathrm{n}=62)\end{array}$ & $\begin{array}{l}\text { Dikkat } \\
\text { Eksikliğinin } \\
\text { Baskın } \\
\text { Olduğu Tip } \\
(\mathrm{n}=11)\end{array}$ & $\mathrm{F}(1.72)$ & $\mathrm{p}$ \\
\hline Nefes Sorunları & $1.5 \pm 1.6$ & $.63 \pm 1.3$ & 2.5 & 0.12 \\
\hline Davranışsal Sorunlar & $10.6 \pm 3.7$ & $7.1 \pm 1.4$ & 9.6 & 0.003 \\
\hline Uykululuk & $0.24 \pm 0.56$ & $0 \pm 0$ & 2.0 & 0.16 \\
\hline Diğer & $1.21 \pm 0.94$ & $0.64 \pm 0.66$ & 3.7 & 0.06 \\
\hline Toplam & $0.61 \pm 0.20$ & $0.38 \pm 0.11$ & 13.9 & $<0.001$ \\
\hline Toplam Uyku & $0.18 \pm 0.15$ & $0.08 \pm 0.10$ & 4.6 & 0.04 \\
\hline
\end{tabular}


Tablo 3: Eştanı olan ve olmayan hastaların puanlarının karşılaştırılması.

\begin{tabular}{|l|l|l|l|c|}
\hline Puan & $\begin{array}{l}\text { Eş hastalanım } \\
\text { yok } \\
(\mathrm{n}=45)\end{array}$ & $\begin{array}{l}\text { Eş hastalanım } \\
\text { var } \\
(\mathrm{n}=28)\end{array}$ & $\mathrm{F}(1.72)$ & $\mathrm{p}$ \\
\hline Nefes Sorunları & $1.3 \pm 1.4$ & $1.4 \pm 1.8$ & 0.07 & 0.78 \\
\hline Davranışsal Sorunlar & $10.1 \pm 3.6$ & $2.1 \pm 1.5$ & 0.09 & 0.77 \\
\hline Uykululuk & $0.20 \pm 0.53$ & $0 \pm 0$ & 2.24 & 0.138 \\
\hline Diğer & $1.12 \pm 0.92$ & $0.63 \pm 0.66$ & 0.80 & 0.374 \\
\hline Toplam & $0.58 \pm 0.21$ & $0.16 \pm 0.11$ & 0.10 & 0.75 \\
\hline Toplam Uyku & $0.16 \pm 0.13$ & $0.17 \pm 0.17$ & 0.25 & 0.88 \\
\hline
\end{tabular}

0.2 \pm 0.5 ; Kontrol: $0 \pm 1,5, F(1,112)=6.2, p=0.014)$, Diğer Sorunlar (DEHB: 1,12 \pm 0.9 ; Kontrol: 0.6 \pm $0.6, F(1,112)=8.86, p=0.004)$ ve Toplam (DEHB: $0.58 \pm 0.2$; Kontrol: $0.16 \pm 0.1, F(1,112)=142.7$, $p<0.0001)$ puanları anlamlı olarak daha yüksektir. Toplam puandan Davranışsal Sorunlar alt ölçeği puanı çıkarılarak tekrar hesaplandığında da uyku sorunlarının yine DEHB olgularında daha fazla olduğu gö-rülmektedir (DEHB: $0.16 \pm 0.15$; Kontrol: $0.09 \pm 0.08, F(1,112)=8.6$, $\mathrm{p}=0.004)$. Aynı şekilde, ölçeğin kesme puanı olan 0.33 puanından daha yüksek alan olguların oranı DEHB grubunda $(n=61, \% 83.6)$ kontrol grubundan $(n=3, \% 7.3)$ anlamlı olarak daha yüksektir (x2=61.9, $p<0.001)$.

DEHB bileşik tip $(n=62)$ ve dikkat eksikliğinin baskın olduğu tip $(n=11)$ (DEB) olgularının karşılaştırıması Tablo 2'de, eştanı olan $(n=28)$ ve olmayan $(n=45)$ hastaların puanları da Tablo 3'de özetlenmiştir. Tablolarda da izlendiği gibi DEHB bileşik tip olan olguların davranışsal sorunları (DEHB Bileşik:10.6 \pm 3.7 ; DEHB Dikkat Eksikliği: $7.1 \pm 1.4, F(1,72)=9.6, p=0.016)$ ve toplam uyku sorunları (DEHB Bileşik: $0.61 \pm 0.2$; DEHB Dikkat Eksikliği: $0.38 \pm 0.11$, $F(1,72)=13.9, p<0.001)$ dikkat eksikliğinin önde olduğu tip olgularından daha yüksektir. Toplam puandan Davranışsal Sorunlar alt ölçeği puanı çıkarılarak tekrar hesaplandığında da uyku sorunlarının yine DEHB bileşik tip olgularında daha fazla olduğu görülmektedir (DEHB Bileşik: $0.18 \pm 0.15$; DEHB Dikkat Eksikliği: 0.08 \pm 0.1 , $F(1,72)=4.6, p=0.04)$. Eştanı varlığı ölçek puanIarını anlamlı bir şekilde etkilememektedir $(F(1,72)=0.07-2.24 ; p=0.14-0.88)$.

\section{TARTIȘMA}

Araştırmanın sonuçları, DEHB'lu çocuklarda genel olarak uyku sorunlarının kontrol olgularından anlamlı oranda yüksek olduğunu göstermektedir. PUÖ de yer alan DEHB ile ilişkili maddeler çıkarıldıktan sonra da anlamlı oranda fark bulunması, önceki çalışmalarda sıkça vurgulandığı üzere (Owens 2005, Corkum ve ark 1998, Van Der Heijden ve ark 2005) annebabaların DEHB'lu çocuklarında kontrollere kıyasla oldukça fazla oranda uyku ile ilgili sorun bildirdiklerine işaret etmektedir. Öznel ölçüm araçlarıyla yapılan çalışmalar çoğunlukla bu ortak sonucu verirken, polisomnografi, MLST, aktigrafi gibi daha nesnel ölçüm araçları kullanılarak yapılan araştırmaların sonuçları daha karışıktır ve tutarlı bir sonuç vermemektedir 
(Sadeh ve ark 2006). Araştırmamızda eştanı varlığı uyku sorunlarının artışı ile paralellik göstermektedir. Bu da depresyon, anksiyete bozukluğu gibi bir çok psikiyatrik bozuklukta uyku sorunlarının sık görülmesi ile uyumludur. DEHB grubunda DEB grubuna göre daha fazla uyku sorunu saptanmıştır. Hiperaktivitenin doğrudan uykuya dalma ve sürdürmeyle ilgili sorunlarla ilişkili olabileceğini düşündürmektedir. Nefes almayla ilgili uyku sorunları bu araştırmada DEHB grubunda kontrollerden yüksek bulunmakla birlikte istatistiksel olarak anlamlı düzeyde bir fark tespit edilmemiştir. Bu tür uyku sorunlarının DEHB grubunda daha fazla bulunduğuna dair yayınlar (Owens ve ark 2000) olduğu gibi bunu saptamayan yayınlar (Crabtree ve ark 2003) da bulunmaktadır.

DEHB olan çocuklarda uyku bozukluklarına iliş̧kin araştırmaların önemli bir kısmında yöntem sorunları bulunmaktadır (Cortese ve ark 2006). Standart tanı sistemlerinin kullanılmama$\mathrm{Sı}$, tanı alt gruplarının belirtilmemesi, eş zamanlı tanıların bulunması, olgu yanılma payını yükseltecek şekilde uyku sorunu ile doğrudan başvuranlar arasından seçilmesi, eşzamanlı ilaç kullanımı olması, yaş gruplarına göre örneklemin homojen seçilmemesi ve polisomnografi için bir uyum gecesinin ertesinde çekim yapılmaması bunların başlıcaları olarak sayılabilir (Sadeh ve ark 2006).

Çalışmada standart tanı sistemlerinin kullanılması, alt grupların ve eştanıların bu yöntemle belirlenmiş olması ve ilk kez tanı konulmuş, ilaç kullanımı olmayan bir örneklemin dahil edimiş olmasının çalışmanın güçlü yanları olduğu düşünülmektedir. Ayrıca olguların hiçbirisi uyku bozukluğu yakınması ile başvurmamış, bu açıdan yönlendirilen hastalar örnekleme dahil edilmemiştir. Örneklem seçimindeki tüm bu olumlu yanlara rağmen yaş dağılımının homojen olmaması ve sayının görece olarak az olmasından araştırmanın kısıtlılıkları olarak bahsedilebilir. Çalışmada kullanılan PUÖ'nin Türkçe geçerlik ve güvenirliğinin henüz tamamlanmamış olması; Polisomnografi, aktigrafi, MLST gibi nesnel ölçüm araçlarının araştırmaya dahil edilememiş olması da çalışmanın diğer kısıtılıkları arasındadır. Ancak ülkemizde uyku laboratuvarlarının ne kadar az sayıda olduğu ve bunların da ne kadarının çocuk-ergen grubuna hizmet verebildiği göz önünde bulundurulursa bu durumun aslında ülkemizin kısıtlı şartlarının bir sonucu olduğu daha iyi anlaşılabilecektir.

Sonuç olarak, DEHB olgularında uyku sorunları günümüzde giderek daha fazla ilgi çekmektedir. Bulgular, DEHB'na uyku sorunlarının sıklıkla eşklik ettiğine; gidişini olumsuz etkilediğine; aile ve çocuk üzerinde ek yük getirdiğine; hem ayırıcı tanı hem tedavi açısından ayrıca ele alınmaları gerektiğine işaret etmektedir (Van Der Heijden ve ark 2005). Bulguların klinik önemi ise DEHB teşhisi konulan olguların uyku sorunları hakkında daha dikkatli sorgulanması ve erken saptanarak hastalığın gidişi üzerindeki olumsuz etkilerinin giderilmesi gerektiğini vurgulamasıdır.

$\mathrm{Bu}$ araştırmanın ülkemiz DEHB çocuklarında uyku sorunlarını ilk olarak inceleyen araştırma olması açısından yazına katkıda bulunacağı düşünülmektedir. 


\section{KAYNAKLAR}

Biederman J, Faraone SV (2005) Attention Deficit Hyperactivity Disorder. Lancet 366(9481): 237248.

Chervin RD, Archbold KH (2001) Associations Between Symptoms of Attention, Hyperactivity, Restless Legs and Periodic Leg Movements. Sleep, 25: 213-215.

Chervin RD, Hedger K, Dillon JE, Pituch KJ (2000) Pediatric Sleep Questionnaire (PSQ): Validity and Relaibility of Scales for Sleep-Disordered Breathing, Snoring, Sleepiness and Behavioral Problems. Sleep Med, 1(1): 21-32.

Corkum P, Tannock R, Moldofsky H (1998) Sleep Disturbances in Children with Attention Deficit Hyperactivity Disorder. J Am Acad Child Adolesc Psychiatry, 37(6): 637-646.

Cortese S, Konofal E, Yateman N, Mouren MC, Lecendeux M (2006) Sleep and Alertness in Children with Attention Deficit Hyperactivity Disorder: A Systematic Review of the Literature. Sleep, 29 (4): 504511.

Crabtree VM, Ivanenko A, Gozal D (2003) Clinical and Parentel Assessment of Sleep in Children with Attention Deficit/Hyperactivity Disorder Refferred to A Pediatric Sleep Medicine Center. Clin Pediatr, 42: 807-813.

Diagnostic and Statistical Manuel of Mental Disorders, 4th ed. (2004) American Psychiatric Association ed., Washington.

Efron D, Jarman F, Barker M (1997) Side Effects of Methylphenidate and Dextroamphetamine in
Children with Attention Deficit Hyperactivity Disorder: A Double-Blind, Crossover Trial. Pediatrics, 100: 662666.

Golan N, Shahar E, Ravid S, Pillar G (2004) Sleep Disorders and Day Time Sleepiness in Children with Attention Deficit Hyperactivity Disorder. Sleep, 27: 261-266.

Gökler B, Ünal F, Pehlivantürk B, Kültür EÇ, Akdemir D, Taner Y (2004) Okul Çağı Çocukları İçin Duygulanım Bozuklukları ve Şizofreni Görüşme Çizelgesi -Şimdi ve Yaşam Boyu Şekli- Türkçe Uyarlamasının Geçerlik ve Güvenirliği. Çocuk ve Ergen Ruh Sağlığı Dergisi 11(3): 109-116.

Huang YS, Chen NH, Li HY, Wu YY, Chao CC, Guilleminault C (2004) Sleep Disorders in Taiwanese Children with Attention Deficit Hyperactivity Disorder. J Sleep Res, 13: 269-277.

Kaufman J, Birmaher B, Brent DA, Rao U, Flynn C, Moreci P, Williamson D, Ryan ND (1997) Schedule for Affective Disorders and Schizophrenia for SchoolAge Children Present and Lifetime Version (K-SADSPL): Initial Relaibility and Validity Dat. J Am Acad Child Adolesc Psychiatry, 36(7): 545-553.

Owens JA (2005) The ADHD and Sleep Conondrum: A Review. J Dev Behav Pediatr, 26(4): 312-322.

Owens JA, Maxim R, Nobile C, Mcguinn M, Msall M (2000) Parental and Self-Report of Sleep in Children with Attention Deficit Hyperactivity Disorder. Arch Pediatr Adolesc Med, 154: 549-555.

Van Der Heijden KB, Smiths MG, Gunning WB (2005) Sleep-Related Disorders in ADHD: A Review. Clin Pediatr, 44(3): 201-210. 
